\title{
Preventing Covert Brain Infarct-Related Cognitive Impairment and Dementia
}

\author{
Romella Durrani (iD, Michael D. Hill $\mathbb{D}$, Eric E. Smith (D)
}

\begin{abstract}
Covert brain infarcts (CBIs) are five times more prevalent than symptomatic brain infarcts. CBIs are associated with cognitive impairment and therefore may be a target for preventing cognitive decline and dementia. This review focuses on strategies for preventing CBI-related cognitive impairment, either by preventing incident or recurrent CBI or by enhancing cognitive reserve. CBIs begin to become prevalent during midlife and are highly prevalent in later life. The distribution of vascular pathologies of CBI differs from those that cause symptomatic stroke; therefore, preventive treatments may need to differ as well. Only a few randomized clinical trials have provided data on CBI prevention, without conclusive results. Limited data suggest that higher early-life education, hypothesized to enhance cognitive reserve, can protect the brain from effects of CBI.
\end{abstract}

RÉSUMÉ : La prévention des troubles cognitifs et de la démence à la suite d'un accident ischémique cérébral. Les infarctus cérébraux silencieux (ICS) sont cinq fois plus fréquents que les accidents ischémiques cérébraux qui présentent des symptômes. Les ICS sont aussi associés à l'apparition de troubles cognitifs, de sorte qu'il y aurait lieu de les cibler dans la prévention du déclin cognitif et de la démence. Cette étude entend mettre l'accent sur les risques associés aux ICS et sur de possibles pistes et stratégies dans la prévention du déclin cognitif lié aux ICS, que ce soit en prévenant leur incidence ou leur récurrence ou en améliorant la réserve cognitive des individus. Il faut savoir que les ICS commencent à se manifester vers la quarantaine et deviennent très fréquents plus tard dans la vie. De plus, la répartition des pathologies vasculaires liées aux ICS diffère de celle qu'on associe aux accidents ischémiques qui présentent des symptômes. Il est par conséquent possible que les traitements préventifs puissent différer. Seuls quelques essais cliniques randomisés ont fourni des données au sujet de la prévention des ICS, et ce, sans résultats concluants. Des données limitées suggèrent par ailleurs qu'une éducation plus poussée dès le plus jeune âge (on fait l'hypothèse que cela améliore la réserve cognitive des individus) peut protéger le cerveau contre les effets des ICS.

Keywords: Covert brain infarct, Subclinical stroke, Silent brain infarct, Cognitive impairment, Dementia, Cognitive reserve, Mild behavioral impairment

doi:10.1017/cjn.2020.45

Can J Neurol Sci. 2020; 47: 456-463

\section{INTRODUCTION}

Covert (or "silent") brain infarcts (CBIs) are commonly identified on brain imaging in older persons without a clinically recognized history of symptomatic stroke. They can be subtyped based on location and appearance as lacunes, recent small subcortical infarcts, microinfarcts, or less often, larger subcortical infarcts or cortical infarcts; however, the majority of CBIs are small. ${ }^{1,2}$ In the general elderly population, $80-90 \%$ of CBIs are subcortical, and $>90 \%$ of these subcortical infarcts are lacunes (Figure 1). ${ }^{2}$ The pathophysiology of lacunes is complex, and it is a matter of ongoing debate whether some lacunes may be caused by processes other than thrombotic or embolic occlusion with subsequent infarction ${ }^{3}$; however, for the purpose of this review, we include all lacunes under the umbrella term of CBI.

CBIs are five times more prevalent than symptomatic brain infarcts. In the USA, as many as 11 million individuals may suffer from CBI every year. ${ }^{4-6}$ Although CBIs do not exhibit acute overt clinical symptoms, they are associated with subtle deficits in physical, neurological, and cognitive function that usually go undiagnosed. ${ }^{1,6}$ Community-based autopsy investigations show that most of the vascular contributions to dementia risk are due to small infarcts without clinical stroke, mostly caused by cerebral small vessel disease (CSVD). ${ }^{7}$ Despite their prevalence and association with diverse clinical impairments, there have been few clinical trials for CBI.

Preventing CBI may therefore be a potentially powerful way to reduce risk for cognitive decline and dementia. In this article, we briefly discuss what is known about CBI epidemiology, pathophysiology, and cognitive consequences, followed by review of risk factors for CBI (as it is logical that treating these risk factors should reduce the incidence of CBI and thus preserve cognition), enhancing cognitive reserve (as this is a potential strategy to sustain cognitive function despite CBI), and the current clinical trial literature and its limitations.

From the Department of Clinical Neurosciences, Cumming School of Medicine, University of Calgary, Calgary, Alberta, Canada (RD, MDH, EES); Hotchkiss Brain Institute, University of Calgary, Calgary, Alberta, Canada (RD, MDH, EES); Department of Community Health Sciences and Radiology, Cumming School of Medicine, University of Calgary, Alberta, Canada (MDH, EES); Department of Medicine, Cumming School of Medicine, University of Calgary, Calgary, Alberta, Canada (MDH).

Received November 6, 2019. Final Revisions Submitted February 19, 2020. Date of Acceptance February 24, 2020.

Correspondence to: Eric E. Smith, Health Sciences Centre, University of Calgary, Room 2941, 3330 University Dr. NW, Calgary, Alberta, Canada, T2N 4N1. Email: eesmith@ ucalgary.ca 


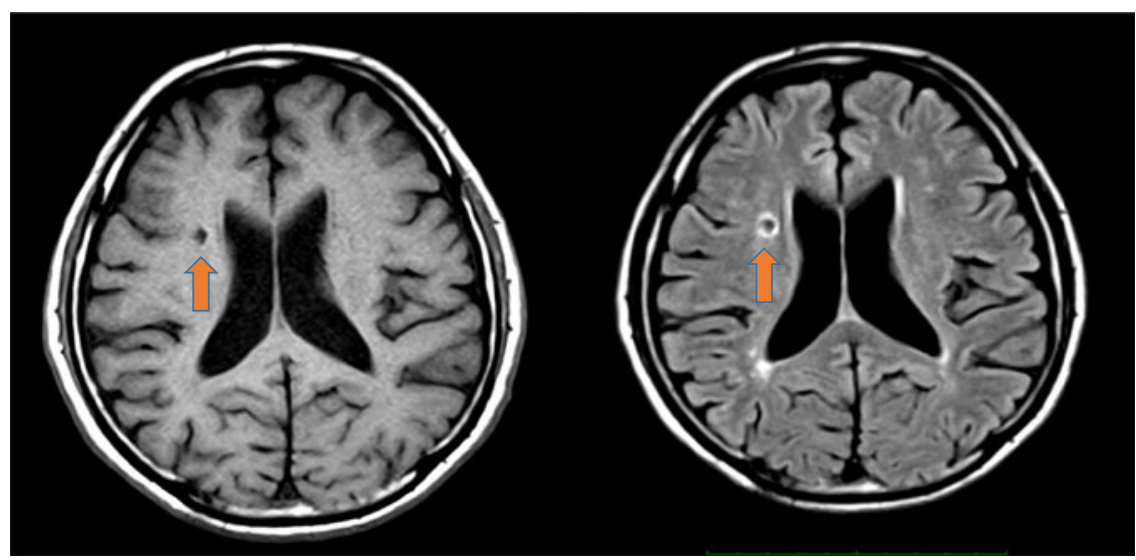

T1-weighted

FLAIR

Figure 1: Lacune. Lesion of $8-9 \mathrm{~mm}$ in the right subcortical white matter, with low signal intensity on T1-weighted sequence and peripheral hyperintense rim with central hyposignal intensity on FLAIR sequence. FLAIR=fluid-attenuated inversion recovery.

\section{Prevalence and Incidence of CBIs}

Autopsy studies are the gold standard for identifying brain infarcts. In life, CBI can be identified on computed tomography or magnetic resonance imaging (MRI), with the latter being more sensitive. CBIs are a frequent incidental MRI finding. ${ }^{2,8}$ The STandards for ReportIng Vascular Changes on NEuroimaging provides criteria for radiological identification of lacunes and recent small subcortical infarcts, appropriate for use in clinical care and research practice. ${ }^{9}$

The prevalence and incidence of CBI are higher than symptomatic stroke. ${ }^{6}$ The MRI-defined prevalence of CBI in the healthy general population is approximately $11 \%$ for ages $55-64,22 \%$ for ages $65-69,28 \%$ for ages $70-74,32 \%$ for ages $75-79,40 \%$ for ages $80-85$, and $43 \%$ for ages $\geq 85$. $^{10-12}$ One study reported a $30-40 \%$ higher prevalence of CBI in women compared to men, but this finding has not been replicated in other studies. ${ }^{4,6,11,13}$ Autopsy studies are concordant with neuroimaging studies in showing a high prevalence of CBI. For example, a Japanese population-based autopsy study found an overall CBI prevalence of $12.9 \%$ in persons with a mean age at death of $78.3 \pm 9.5 .{ }^{14}$ In addition to older age, other high-risk groups for CBI and CBI-associated cognitive impairment include patients undergoing cardiovascular and neurovascular surgery, and patients with sickle cell disease. ${ }^{6}$

\section{Pathophysiology of CBIs}

The dominant view is that, like symptomatic acute ischemic stroke, most CBIs result from thrombotic or embolic arterial occlusion $^{2}$ (Figure 2). In the case of lacunes and microinfarcts, thrombosis or hypoperfusion may result from arteriolar wall thickening, hyalinization, and endothelial dysfunction. Additionally, branch occlusive disease, atheroembolism from proximal arterial sources, or cardioembolism from atrial fibrillation or other cardiac diseases can occur. However, it is difficult to prove that lacunes and microinfarcts are always caused by vascular occlusion because the involved arteries are too small to visualize by conventional neuroimaging. Even at autopsy, the involved vessels may be too small to identify or may have recanalized or otherwise changed in the interval between CBI and death. High-field-strength MRI (7 T) is beginning to demonstrate acute occlusions in some patients. ${ }^{15}$ Other mechanisms are also probably at play. A recent comprehensive review summarizes strong evidence that blood-brain barrier dysfunction, impaired vascular reactivity, and vessel wall damage occur in patients with diffuse CSVD, and some of these mechanisms may lead to ischemia or damage the brain independent of ischemia. ${ }^{3}$ Another review also suggests that ischemia is one of the mechanisms involved in lacunes. ${ }^{16}$ A better understanding of these mechanisms may lead to complementary novel therapeutic approaches for preventing lacunar disease that are distinct from the conventional approach of blood pressure control, statins, diabetes prevention and treatment, and antithrombotic medications that have proved successful in preventing atherosclerotic stroke. ${ }^{17}$

\section{CBI and Cognitive and Behavioral Impairment}

CBIs are associated with cognitive impairment and dementia. ${ }^{6}$ Cross-sectional studies generally find that the presence of $\mathrm{CBI}$ is associated with lower performance on cognitive screening tests such as Mini-Mental State Examination or Montreal Cognitive Assessment, and on neuropsychological tests. ${ }^{18,19}$ Acute CBIs, which can rarely be detected incidentally on neuroimaging, are more common in cognitively impaired persons. ${ }^{20}$ Microinfarcts have been associated with worse cognitive performance. ${ }^{21}$

Non-demented persons with CBI are at higher risk for future cognitive decline and dementia. Two recent systematic reviews provide pooled analyses of future dementia risk in patients with CBI. One review pooled findings from four general population studies and found a hazard ratio (HR) of 1.47 [95\% confidence interval (CI) 0.97-2.22] for the association between CBI and dementia risk, while another review that included both general population and at-risk populations found an HR of 1.37 [95\% CI $0.99-1.89]^{22,23}$

\section{Risk Factors for CBI}

Risk factors for symptomatic stroke have been heavily studied and include factors such as previous history of hypertension or blood pressure $\geq 140 / 90 \mathrm{mmHg}$, physical activity, apolipoprotein (Apo)B/ ApoA1 ratio, diet, waist-to-hip ratio, psychosocial factors, current smoking, cardiac causes, alcohol consumption, and diabetes mellitus. ${ }^{24}$ While these risk factors have been heavily studied in the 


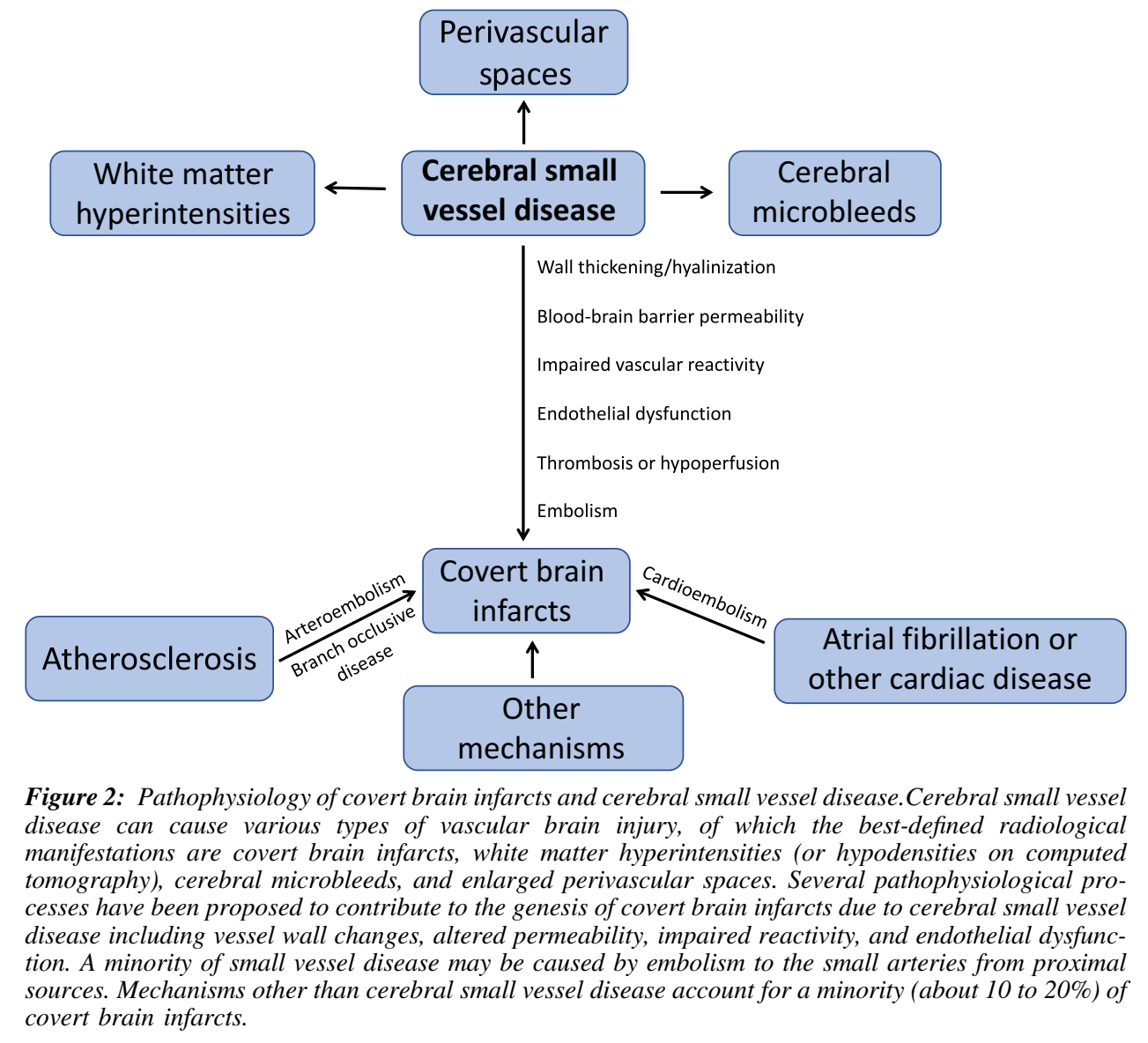

context of symptomatic stroke, CBI risk factors have been less studied. Risk factors for CBI have been investigated in several populationbased studies and have been systematically reviewed, classifying risk factors as "strong," "likely," and "unclear" (Table 1). ${ }^{25}$ The "strong" risk factors were age, hypertension, metabolic syndrome, carotid artery disease, and chronic kidney disease. ${ }^{25}$ Additionally, the "likely" risk factors were coronary artery disease, heart failure, homocysteinemia, and obstructive sleep apnea. ${ }^{25}$ Treating these risk factors may reduce the incidence of $\mathrm{CBI}$.

These risk factors are also well-established risk factors for symptomatic stroke. However, it is unclear which factors are the most important for CBI, and how much of the overall risk they explain. In contrast, a large case-control study shows that ten risk factors account for $90 \%$ of the risk of symptomatic stroke, with hypertension accounting for the largest portion of risk. ${ }^{24}$ Despite the large degree of overlap between risk factors for both CBI and symptomatic stroke, these ten risk factors may not have the same level of importance for CBI, which is predominantly caused by CSVD, in contrast to symptomatic stroke which is predominantly caused by large artery disease or cardioembolism. Studies of the population attributable risk for CBI risk factors will be needed to identify the most important risk factors, which can then be used to guide public health prevention efforts.

A life-course approach to assessing dementia risk is increasingly being adopted, recognizing that risk factors for all-cause dementia may vary according to the life stage in which exposures were assessed. ${ }^{26}$ For example, some studies suggest that hypertension and obesity are associated with dementia risk when ascertained in midlife, but not later life. ${ }^{26}$ However, more long-term studies are required to substantiate the impact of midlife risk factors over laterlife risk factors. Most studies of CBI have either been cross-sectional or have been done in the elderly, with few studies at other life stages. There is a need for longitudinal CBI epidemiology studies at different life stages, including in midlife when neuroimaging evidence of CSVD is beginning to accrue. ${ }^{27}$

Another need is for data on CBI incidence and risk factors from a greater variety of populations, including in low- and middle-income countries. ${ }^{6}$ Little is known about variation in CBI prevalence between countries and between races and ethnicities.

\section{CBI as a Target for Preventing Cognitive Decline and Dementia}

Given the high prevalence of CBI and their association with cognitive disorders, it should be considered a promising target for preventing dementia. Although this review focuses on CBI prevention, many patients with $\mathrm{CBI}$ also have CSVD that causes other brain lesions - including white matter hyperintensities (WMHs), cerebral microbleeds (CMBs), and enlarged perivascular spaces. These brain lesions may also be important causes of cognitive dysfunction and could warrant their own unique prevention strategies. However, in our view, CBI may be the most important focus for a few reasons. CBIs by definition are associated with tissue destruction (manifest as cavitation or encephalomalacia), while this is not clearly the case with $\mathrm{WMH}$, enlarged perivascular spaces, or CMBs. Additionally, an American Heart Association statement has defined CBI as a 
Table 1: Risk factors ${ }^{24,25}$

\begin{tabular}{l|l}
\hline Covert brain infarct risk factors & \multicolumn{1}{c}{$\begin{array}{c}\text { Best established symptomatic } \\
\text { stroke risk factors }\end{array}$} \\
\hline Strong association & Hypertension \\
\hline Age & Physical activity \\
\hline Hypertension & Apolipoprotein (Apo)B/ApoA1 ratio \\
\hline Metabolic syndrome & Diet \\
\hline Carotid artery disease & Waist-to-hip ratio \\
\hline Chronic kidney disease & Psychosocial factors \\
\hline Likely association & Current smoking \\
\hline Coronary artery disease & Cardiac causes \\
\hline Heart failure & Alcohol consumption \\
\hline Homocysteinemia & Diabetes mellitus \\
\hline Obstructive sleep apnea & \\
\hline Unclear association & \\
\hline Atrial fibrillation & \\
\hline Dyslipidemia & \\
\hline Diabetes & \\
\hline Obesity & \\
\hline Alcohol & \\
\hline Tobacco & \\
\hline Ethnicity & \\
\hline Sex & \\
\hline Cover bian & \\
\hline
\end{tabular}

Covert brain infarct risk factors taken from the systematic review by Fanning et al. ${ }^{24}$ Symptomatic stroke risk factors taken from INTERSTROKE study by O'Donnell et al. ${ }^{25}$

form of "stroke," a term that is widely understood by laypersons, patients, health professionals, health administrators, and policy makers. We consider it likely that persons will be more motivated to undertake new lifestyle, behavioral, and pharmacological interventions to prevent "covert stroke" than to prevent "white matter changes" or "larger spaces around arteries." By focusing on "covert stroke," the considerable public health effort to raise awareness for symptomatic stroke can be leveraged.

\section{Preventing CBI-Related Cognitive Decline by Enhancing Cognitive Reserve}

In addition to preventing CBI by addressing risk factors, enhancing resilience to CBI-related injury may be another useful approach to reducing the burden of CBI-related cognitive impairment. Interventions that enhance the brain's ability to compensate for accruing age-related pathologies, such as CBI, could reduce the incidence of dementia even if the buildup of agerelated brain pathology does not change. This concept follows from observations that cognitive performance can vary widely between persons with the same degree of pathology, such as Alzheimer's disease ${ }^{28,29}$ Enhancing cognitive reserve is an attractive approach to reduce the clinical burden of age-related brain pathologies, particularly those that are currently unmodifiable such as Alzheimer's disease.

Cognitive reserve has been defined as the capacity of the brain to actively cope with brain pathologies by compensating for damage, thereby attempting to counteract the effects of these pathologies. ${ }^{28,29}$ Mechanisms for this compensation may include using brain networks more efficiently and enhancing the ability to use alternate brain networks to bypass damaged networks. ${ }^{28,29}$ Brain reserve has been defined as the structural brain features (i.e., brain size, synapse counts, or surrogates of brain size such as head circumference) that influence the clinical expression of a given level of brain pathology. Higher brain reserve is hypothesized to allow some individuals to better cope with pathologies. ${ }^{30}$ With greater brain reserve capacity, more brain damage (i.e., more brain infarcts or greater brain atrophy) is required to reach the threshold for observable cognitive impairment. ${ }^{28,29,31}$

Cognitive and brain reserve have been most commonly studied in the context of Alzheimer's disease and Parkinson's disease, and not CBI. Factors that may enhance cognitive reserve in this context include: education level, intelligence (measured by IQ), occupational attainment (professional, technical, and managerial positions), height, socioeconomic status (includes education, occupation, household income, and wealth), social participation, participation in cognitively stimulating activities, leisure time activities, and physical activity. ${ }^{28,29,32-37}$ However, it is unknown whether certain risk factors such as physical activity improve cognitive reserve through neurophysiological mechanisms or through improving vascular health.

A life-course approach to building resiliency against cognitive decline may be warranted. Similar factors may enhance resilience to CSVD pathology, but so far there are few studies. In the Leukoaraiosis and Disability (LADIS) study, higher education and higher occupational attainment were associated with weaker effects of WMH on cognition, and less decline in cognition. ${ }^{38}$ Education was a significant effect modifier of the effects of WMH on processing speed defined by the Stroop $\mathrm{I}(\beta=-0.09, p=0.02)$ and Stroop II tests $(\beta=-0.08, p=0.04) .{ }^{38}$ Occupational attainment was a significant effect modifier for the effects of WMH on verbal memory measured by Immediate Word Recall $(\beta=0.11$, $p=0.039) .{ }^{38}$ Similarly, education was a significant effect modifier of the effects of lacunes on Delayed Word Recall $(\beta=-0.15$, $p=0.008$ ), while occupational attainment was a significant effect modifier for the effects of lacunes on Immediate and Delayed Word Recall $\left(F=6.1, p=0.014 ; F=6.17, p=0.013\right.$, respectively) ${ }^{38}$ Cognitively stimulating leisure activities have also been identified as an effect modifier of the association between high WMH load and cognition, showing that high leisure activity is associated with significantly better processing speed $(\beta=0.15,95 \%$ CI 0.01 , 0.30 ), despite the presence of high WMH load. ${ }^{39}$

The few studies conducted on CBI-related cognitive decline suggest that those with high levels of education may show less cognitive impairment. ${ }^{6,40}$ A study looked at the effect of education on cognition in the presence of ischemic lesions, finding that women with high ischemic lesion load and high education had significantly less cognitive decline measured on Modified MiniMental State: post high school -0.22 points/year, high school $=-0.13$ points/year, and less than high school -0.94 points/ year. ${ }^{40}$ As mentioned above, in the LADIS study, higher education was associated with a weaker association between lacunes and lower performance on Delayed Word Recall. ${ }^{38}$

The relationship between reserve factors, CBI, and cognition is complex because many reserve factors, in addition to moderating the relationships between $\mathrm{CBI}$ and cognition, may also be risk factors for $\mathrm{CBI}$ or risk factors for cognitive decline 
Table 2: CBI clinical trials ${ }^{43-46,48-50}$

\begin{tabular}{|c|c|c|c|c|c|c|c|c|c|}
\hline Study & Intervention & Control & Outcome & Duration & $\begin{array}{c}\text { Incident CBI in } \\
\text { the intervention } \\
\text { group, } n\end{array}$ & $\begin{array}{l}\text { Incident CBI in the } \\
\text { control group, } n\end{array}$ & $\begin{array}{l}\text { CBI rate in the } \\
\text { intervention } \\
\text { group }(\%)\end{array}$ & $\begin{array}{c}\text { CBI rate in the } \\
\text { control group } \\
(\%)\end{array}$ & Effect size \\
\hline Richard et al. ${ }^{43}$ & Vascular care & Standard care & Lacune incidence & 2 years & 5 & 7 & 15.2 & 25 & - \\
\hline Sharma et al. ${ }^{44}$ & $\begin{array}{l}\text { Aspirin }(100 \mathrm{mg}) \text { OD alone; } \\
\text { or aspirin }(100 \mathrm{mg}) \text { OD plus } \\
\text { rivaroxaban }(2.5 \mathrm{mg}) \mathrm{BID} ; \\
\text { or rivaroxaban }(5 \mathrm{mg}) \mathrm{BID} \\
\text { alone }\end{array}$ & No control - three arms & CBI incidence & Not published & Not published & - & Not published & - & Ongoing trial \\
\hline Hasegawa et al. ${ }^{45}$ & $\begin{array}{l}\text { Perindopril }(4 \mathrm{mg}) \text { OD } \\
\text { (either with or without } \\
\text { indapamide ( } 2 \mathrm{mg} \text { ) OD) }\end{array}$ & Placebo & CBI incidence & Mean 3.9 years & $\begin{array}{l}41 ; 0 \text { in those } \\
\text { with a history of } \\
\text { large artery } \\
\text { infarction }\end{array}$ & $\begin{array}{l}51 ; 7 \text { in those with a history } \\
\text { of large artery infarction }\end{array}$ & $\begin{array}{l}13 \% ; 0 \% \text { in those } \\
\text { with a history of } \\
\text { large artery } \\
\text { infarction }\end{array}$ & $\begin{array}{l}15 \% ; 12 \% \text { in } \\
\text { those with a } \\
\text { history of large } \\
\text { artery infarction }\end{array}$ & - \\
\hline $\begin{array}{l}\text { Sprint Mind } \\
\text { Investigators } \\
\text { et al. }{ }^{46}\end{array}$ & $\begin{array}{l}\mathrm{SBP}<120 \mathrm{mmHg} \\
\text { (intensive treatment) }\end{array}$ & $\begin{array}{l}\mathrm{SBP}<140 \mathrm{mmHg} \\
\text { (standard treatment) }\end{array}$ & $\begin{array}{l}\text { WMH progression and } \\
\text { decrease in brain volume }\end{array}$ & $\begin{array}{l}\text { Median } \\
3.40 \text { years }\end{array}$ & - & - & - & - & - \\
\hline Cavalieri et al. ${ }^{48}$ & $\begin{array}{l}\text { B-vitamin ( } 2 \mathrm{mg} \text { folic acid, } \\
25 \mathrm{mg} \text { vitamin } \mathrm{B}_{6} \text {, and } \\
\left.0.5 \mathrm{mg} \text { vitamin } \mathrm{B}_{12}\right)\end{array}$ & Placebo & Lacune incidence & 2 years & 14 & 11 & $8 \%$ & $5.9 \%$ & $\begin{array}{l}\text { OR } 1.38 ; 95 \% \mathrm{CI} \\
\text { not reported }\end{array}$ \\
\hline Van Dalen et al. ${ }^{49}$ & $\begin{array}{l}\text { Nurse-led intensive } \\
\text { cardiovascular care }\end{array}$ & Standard care & Lacunar infarct incidence & 6 years & 6 & 2 & $9 \%$ & $3 \%$ & $\begin{array}{l}\text { OR } 2.2 ; 95 \% \text { CI } \\
0.4-12.1\end{array}$ \\
\hline Stephen et al. ${ }^{50}$ & $\begin{array}{l}\text { Diet, exercise, cognitive } \\
\text { training, and management } \\
\text { of vascular risk factors }\end{array}$ & $\begin{array}{l}\text { Nutritional advice, gym } \\
\text { and aerobic exercise } \\
\text { sessions, cognitive } \\
\text { training, and } \\
\text { management of risk } \\
\text { factors }\end{array}$ & $\begin{array}{l}\text { Cognitive function; MRI } \\
\text { measures (WMH volume, } \\
\text { cortical thickness, and } \\
\text { regional brain volumes) }\end{array}$ & 2 years & - & - & - & - & - \\
\hline
\end{tabular}

$\mathrm{BID}=$ twice per day; $\mathrm{CI}=$ confidence interval; $\mathrm{OD}=$ per day; $\mathrm{OR}=$ odds ratio; $\mathrm{SBP}=$ systolic blood pressure; $\mathrm{WMH}=$ white matter hyperintensity. 
independent of CBI. For example, there is evidence that late-life physical activity may increase cognitive resilience ${ }^{41}$ and that childhood factors such as IQ are associated with later-life WMH burden. ${ }^{42}$ Large datasets with advanced methods such as structural equation modeling may be needed to disentangle these complex relationships.

\section{Clinical Trials of CBI Prevention}

Because of the absence of adequately powered clinical trials, there is no consensus on how to prevent CBI. ${ }^{2}$ Although there are no clinical trials with $\mathrm{CBI}$ as the primary outcome, there are a few substudies of clinical trials that include MRI in a subset of participants, with MRI-defined endpoints (Table 2). There are no definitive results from these studies because they have been underpowered to show differences. However, they do establish proof of concept that MRI endpoints are feasible in clinical trials.

Two studies have looked at the effect of antithrombotic medications for preventing CBI. In the Evaluation of Vascular Care in Alzheimer's Disease study, patients with mixed Alzheimer's disease dementia and small vessel disease randomly assigned to comprehensive vascular care had a similar number of new covert lacunes compared with standard care (5/36 vs. 7/29 treated for 2 years, $p=0.26){ }^{43}$ An MRI substudy of the Cardiovascular Outcomes for People Using Anticoagulation Strategies trial is planned and the trial protocol has been published. ${ }^{44}$ The MRI substudy $(n=1760)$ will show whether CBI incidence differed in participants randomly assigned to take either aspirin $(100 \mathrm{mg})$ per day (OD) alone, aspirin $(100 \mathrm{mg})$ OD plus rivaroxaban $(2.5 \mathrm{mg}$ ) twice per day (BID), or rivaroxaban $(5 \mathrm{mg}) \mathrm{BID}$ was reduced to a similar degree. ${ }^{44}$ Baseline MRI showed that $34.8 \%$ had CBI, a much higher prevalence than the $4.5 \%$ with a clinical history of prior symptomatic stroke, demonstrating that MRI may be able to increase statistical power by detecting more events in fewer participants. ${ }^{44}$

Randomized trials of antihypertensives have so far provided mixed results on whether blood pressure lowering reduces the risk of cognitive decline or dementia. Two such trials have included MRI substudies. In the Perindopril Protection Against Recurrent Stroke Study (PROGRESS) study, patients with a history of stroke were randomly assigned to take either perindopril (4 mg) OD, either in combination with indapamide $(2 \mathrm{mg}$ ) OD or alone, or placebo (treated for mean 3.9 years). ${ }^{45}$ There was no significant difference in the total number of new CBI between active and placebo arms. ${ }^{45}$ However, significantly more participants developed new CBI among those who had a history of large artery infarction and received placebo, compared to those who had a history of large artery infarction and received active treatment $(7 / 55$ vs. $0 / 40, p=0.02) .{ }^{45}$ An MRI substudy of the Systolic Blood Pressure Intervention Trial showed that participants randomly assigned to a systolic blood pressure target of $<120 \mathrm{mmHg}$ compared with $<140 \mathrm{mmHg}$ (treated for median 3.40 years) had less WMH progression and decreased brain volume; however, the incidence of new CBI was not reported. ${ }^{46}$ Ongoing studies are testing the effects of antihypertensives on cerebral blood flow. ${ }^{47}$

In the VITAmins TO Prevent Stroke trial, patients with a recent history of stroke were randomly assigned to take either B-vitamins (2-mg folic acid, 25-mg vitamin $\mathrm{B}_{6}$, and $0.5-\mathrm{mg}$ vitamin $\mathrm{B}_{12}$ ) or placebo for 2 years. ${ }^{48}$ Despite a significant reduction in median WMH volume change in a subset of participants with severe baseline CSVD who received B-vitamins compared to placebo $\left(0.3\right.$ vs. $\left.1.7 \mathrm{~cm}^{3}, p=0.039\right)$, there was no significant difference in the number of new lacunes on MRI between participants who received B-vitamins compared to placebo ( 8 vs. $5.9 \%, p=0.43) .^{48}$

Two trials of comprehensive vascular risk reduction for dementia prevention have included MRI substudies. In the Prevention of Dementia by Intensive Vascular Care trial, a 6-year nurse-led intensive cardiovascular care regimen did not reduce the incidence of new lacunar infarcts on MRI ( $n=126 ; 64$ randomized to active treatment) compared with control intervention (odds ratio (OR) 2.2, 95\% CI 0.4-12.1, $p=0.36$; six intervention participants and two control participants had new lacunar infarcts). ${ }^{49}$ The Finnish Geriatric Intervention Study to Prevent Cognitive Impairment and Disability trial showed that nutrition, exercise, cognitive training, and management of vascular risk factors (2-year intervention) improved cognitive function; a small MRI substudy of 112 patients did not find differences in WMH volume between groups but the effect on infarcts was not reported. ${ }^{50}$

Trials for treating vascular dementia have recently been systematically reviewed. ${ }^{51}$ Interventions included vasodilators, antithrombotic medications, and neuroprotectants. ${ }^{51}$ However, none of the reviewed trials reported whether these interventions prevented new brain infarcts. ${ }^{51}$

\section{Conclusions and Future Directions}

CBIs are highly prevalent with aging, and the appearance of new CBI is associated with cognitive decline and dementia. They share many risk factors with symptomatic stroke. However, the epidemiological story of CBI is not complete. More data are needed on CBI incidence, and from non-Western countries and non-White populations. Associations with conventional vascular risk factors are well established, but more data are needed on lifestyle and behavioral risk factors. A life-course approach is needed to examine how exposures to risk factors in different stages of life influence the risk of later-life CBI.

The associations of modifiable vascular risk factors with $\mathrm{CBI}$ suggest that they may be preventable. However, this can only be proven by clinical trials. Given the expense of MRI, we consider it unlikely that widespread MRI screening will be part of the solution to reducing CBI-related cognitive decline. Instead, research is needed on how to identify persons at risk for CBI using feasible screening methods (including medical history and blood pressure) followed by interventions proven by clinical trials to reduce CBI incidence and enhance cognitive reserve. This targeted screening strategy should be accompanied by a complementary public health strategy to promote better brain health, free of CBI, informed by epidemiological research identifying the most important risk factors for CBI throughout the life span.

\section{ACKNOWLEDGMenTs}

We would like to thank Dr. Feryal Saad for providing us MRI images of CBI.

\section{CONFLICT OF INTEREST}

Ms. RD has nothing to disclose. Dr. EES reports consulting fees from Portola Pharmaceuticals and Alnylam Pharmaceuticals, and royalties from UptoDate. Dr. $\mathrm{MDH}$ has no disclosures 
directly relevant to this manuscript. Outside the submitted work, Dr. MDH reports personal fees from Merck, non-financial support from Hoffmann-La Roche Canada Ltd, grants from Covidien (Medtronic), grants from Boehringer-Ingleheim, grants from Stryker Inc., grants from Medtronic LLC, and grants from NoNO Inc. In addition, Dr. MDH has a patent Systems and Methods for Assisting in Decision-Making and Triaging for Acute Stroke Patients pending to US Patent office Number: 62/086,077 and owns stock in Calgary Scientific Incorporated, a company that focuses on medical imaging software, is a director of the Canadian Federation of Neurological Sciences, a not-for-profit group, is a director of Circle NeuroVascular Inc., and has received grant support from Alberta Innovates Health Solutions, Canadian Institutes of Health Research, Heart and Stroke Foundation of Canada, and National Institutes of Neurological Disorders and Stroke.

\section{Statement of Authorship}

$\mathrm{RD}$ wrote the draft and revised the manuscript. MDH and EES edited and revised the manuscript.

\section{REFERENCES}

1. Sacco RL, Kasner SE, Broderick JP, et al. An updated definition of stroke for the 21 st Century a statement for healthcare professionals from the American Heart Association/American Stroke Association. Stroke. 2013;44(7):2064-89.

2. Smith EE, Saposnik G, Biessels GJ, et al. Prevention of stroke in patients with silent cerebrovascular disease: a scientific statement for healthcare professionals from the American Heart Association/American Stroke Association. Stroke. 2017;48(2):e44-71.

3. Wardlaw JM, Smith C, Dichgans M. Small vessel disease: mechanisms and clinical implications. Lancet Neurol. 2019;18(7): 684-96.

4. Vermeer SE, Koudstaal PJ, Oudkerk M, Hofman A, Breteler MMB. Prevalence and risk factors of silent brain infarcts in the population-based Rotterdam Scan Study. Stroke. 2002;33(1):21-5.

5. Leary MC, Saver JL. Annual incidence of first silent stroke in the United States: a preliminary estimate. Cerebrovasc Dis. 2003;16(3):280-5.

6. Vermeer SE, Longstreth WT, Koudstaal PJ. Silent brain infarcts: a systematic review. Lancet Neurology. 2007;6(7):611-9.

7. Schneider JA, Arvanitakis Z, Bang W, et al. Mixed brain pathologies account for most dementia cases in community-dwelling older persons. Neurology. 2007;69(4):2197-204.

8. Vernooij MW, Ikram MA, Tanghe HL, et al. Incidental findings on brain MRI in the general population. $\mathrm{N}$ Engl $\mathrm{J}$ Med. 2007;357(18):1821-8.

9. Wardlaw JM, Smith EE, Biessels GJ, Bennett DA. Neuroimaging standards for research into small vessel disease and its contribution to ageing and neurodegeneration. Lancet Neurol. 2013;12(8): 822-38.

10. Roger VL, Go AS, Lloyd-Jones DM, et al. Heart disease and stroke statistics-2011 update: a report from the American Heart Association. Circulation. 2011;123(4):e18-209.

11. Howard G, Wagenknecht LE, Cai J, Cooper L, Kraut MA, Toole JF. Cigarette smoking and other risk factors for silent cerebral infarction in the general population. Stroke. 1998;29(5):913-7.

12. Bryan RN, Wells SW, Miller TJ, et al. Infarctlike lesions in the brain: prevalence and anatomic characteristics at MR imaging of the elderly-data from the Cardiovascular Health Study. Radiology. 1997;202(1):47-54.

13. Longstreth WT, Jr., Bernick C, Manolio TA, Bryan N, Jungreis CA, Price TR. Lacunar infarcts defined by magnetic resonance imaging of 3660 elderly people: the Cardiovascular Health Study. Arch Neurol. 1998;55(9):1217-25.
14. Shinkawa A, Ueda K, Kiyohara Y, et al. Silent cerebral infarction in a community-based Autopsy Series in Japan - the Hisayama Study. Stroke. 1995;26(3):380-5.

15. Miyazawa $H$, Natori $T$, Kameda $H$, et al. Detecting lenticulostriate artery lesions in patients with acute ischemic stroke using highresolution MRA at 7 T. Int J Stroke. 2019;14(3):290-7.

16. Regenhardt RW, Das AS, Lo EH, Caplan LR. Advances in Understanding the Pathophysiology of Lacunar Stroke: A Review. JAMA Neurol. 2018;75(10):1273-81.

17. Bath PM, Wardlaw JM. Pharmacological treatment and prevention of cerebral small vessel disease: a review of potential interventions. Int J Stroke. 2015;10(4):469-78.

18. Vermeer SE, Prins ND, den Heijer T, Hofman A, Koudstaal PJ, Breteler MM. Silent brain infarcts and the risk of dementia and cognitive decline. N Engl J Med. 2003;348(13):1215-22.

19. Warren MW, Weiner MF, Rossetti HC, McColl R, Peshock R, King KS. Cognitive impact of lacunar infarcts and white matter hyperintensity volume. Dement Geriatr Cogn Dis Extra. 2015;5(1):170-5.

20. Saini M, Suministrado MS, Hilal S, et al. Prevalence and risk factors of acute incidental infarcts. Stroke. 2015;46(10):2722-7.

21. van Veluw SJ, Shih AY, Smith EE, et al. Detection, risk factors, and functional consequences of cerebral microinfarcts. Lancet Neurol. 2017;16(9):730-40.

22. Bos D, Wolters FJ, Darweesh SKL, et al. Cerebral small vessel disease and the risk of dementia: a systematic review and metaanalysis of population-based evidence. Alzheimers Dement. 2018;14(11):1482-92.

23. Debette S, Schilling S, Duperron MG, Larsson SC, Markus HS. Clinical significance of magnetic resonance imaging markers of vascular brain injury: a systematic review and meta-analysis. JAMA Neurol. 2018;76(1):81-94.

24. O’Donnell MJ, Chin SL, Rangarajan S, et al. Global and regional effects of potentially modifiable risk factors associated with acute stroke in 32 countries (INTERSTROKE): a case-control study. Lancet. 2016;388(10046):761-75.

25. Fanning JP, Wong AA, Fraser JF. The epidemiology of silent brain infarction: a systematic review of population-based cohorts. BMC Med. 2014;12:119.

26. Livingston G, Sommerlad A, Orgeta V, et al. Dementia prevention, intervention, and care. Lancet. 2017;390(10113):2673-734.

27. Smith EE, O'Donnell M, Dagenais G, et al. Early cerebral small vessel disease and brain volume, cognition, and gait. Ann Neurol. 2015;77(2):251-61.

28. Stern Y. What is cognitive reserve? Theory and research application of the reserve concept. J Int Neuropsychol Soc. 2002;8(3): $448-60$.

29. Stern Y. Cognitive reserve in ageing and Alzheimer's disease. Lancet Neurol. 2012;11(11):1006-12.

30. Stern Y, Arenaza-Urquijo EM, Bartres-Faz D, et al. Whitepaper: defining and investigating cognitive reserve, brain reserve, and brain maintenance. Alzheimers Dement. 2018. doi: 10.1016/j. jalz.2018.07.219

31. Nitkunan A, Lanfranconi S, Charlton RA, Barrick TR, Markus HS. Brain atrophy and cerebral small vessel disease a prospective follow-up study. Stroke. 2011;42(1):133-8.

32. Armstrong MJ, Naglie G, Duff-Canning S, et al. Roles of Education and IQ in cognitive reserve in Parkinson's disease-mild cognitive impairment. Dement Geriatr Cogn Dis Extra. 2012;2(1):343-52.

33. Reed BR, Dowling M, Farias ST, et al. Cognitive activities during adulthood are more important than education in building reserve. J Int Neuropsychol Soc. 2011;17(4):615-24.

34. Bourassa KJ, Memel M, Woolverton C, Sbarra DA. Social participation predicts cognitive functioning in aging adults over time: comparisons with physical health, depression, and physical activity. Aging Ment Health. 2017;21(2):133-46.

35. Scarmeas N, Stern Y. Cognitive reserve: implications for diagnosis and prevention of Alzheimer's disease. Curr Neurol Neurosci Rep. 2004;4(5):374-80.

36. Scarmeas N, Stern Y. Cognitive reserve and lifestyle. J Clin Exp Neuropsychol. 2003;25(5):625-33. 
37. Singh-Manoux A, Marmot MG, Glymour M, Sabia S, Kivimaki M, Dugravot A. Does cognitive reserve shape cognitive decline? Ann Neurol. 2011;70(2):296-304.

38. Jokinen H, Melkas S, Madureira S, et al. Cognitive reserve moderates long-term cognitive and functional outcome in cerebral small vessel disease. J Neurol Neurosurg Psychiatry. 2016;87(12):1296-302.

39. Saczynski JS, Jonsdottir MK, Sigurdsson S, et al. White matter lesions and cognitive performance: the role of cognitively complex leisure activity. J Gerontol A Biol Sci Med Sci. 2008;63(8):848-54.

40. Rapp SR, Espeland MA, Manson JE, et al. Educational attainment, MRI changes, and cognitive function in older postmenopausal women from the women's health initiative memory study. Int J Psychiatry Med. 2013;46(2):121-43.

41. Gow AJ, Pattie A, Deary IL. Lifecourse activity participation from early, mid, and later adulthood as determinants of cognitive aging: the Lothian Birth Cohort 1921. J Gerontol B Psychol Sci Soc Sci. 2016;72(1):25-37.

42. Backhouse EV, McHutchison CA, Cvoro V, Shenkin SD, Wardlaw JM. Early life risk factors for cerebrovascular disease: a systematic review and meta-analysis. Neurology. 2017;88(10):976-84.

43. Richard E, Gouw AA, Scheltens P, van Gool WA. Vascular care in patients with Alzheimer disease with cerebrovascular lesions slows progression of white matter lesions on MRI the Evaluation of Vascular Care in Alzheimer's Disease (EVA) study. Stroke. 2010;41(3):554-6.

44. Sharma M, Hart RG, Smith EE, et al. Rationale, design, and baseline participant characteristics in the MRI and cognitive substudy of the cardiovascular outcomes for people using anticoagulation strategies trial. Int J Stroke. 2018;1-12.
45. Hasegawa Y, Yamaguchi T, Omae T, Woodward M, Chalmers J, Investigators PCS. Effects of perindopril-based blood pressure lowering and of patient characteristics on the progression of silent brain infarct: the Perindopril Protection against Recurrent Stroke Study (PROGRESS) CT substudy in Japan. Hypertens Res. 2004;27(3):147-56.

46. Sprint Mind Investigators for the SPRINT Research Group, Nasrallah IM, Pajewski NM, et al. Association of intensive vs standard blood pressure control with cerebral white matter lesions. JAMA. 2019;322(6):524-34.

47. Pauls MM, Moynihan B, Barrick TR, et al. The effect of phosphodiesterase-5 inhibitors on cerebral blood flow in humans: a systematic review. J Cereb Blood Flow Metab. 2018;38(2):189-203.

48. Cavalieri M, Schmidt R, Chen C, et al. B vitamins and magnetic resonance imaging-detected ischemic brain lesions in patients with recent transient ischemic attack or stroke: the VITAmins TO Prevent Stroke (VITATOPS) MRI-substudy. Stroke. 2012;43(12):3266-70.

49. van Dalen JW, van Charante EPM, Caan MWA, et al. Effect of long-term vascular care on progression of cerebrovascular lesions magnetic resonance imaging substudy of the PreDIVA Trial (Prevention of Dementia by Intensive Vascular Care). Stroke. 2017;48(7):1842-8.

50. Stephen R, Liu Y, Ngandu T, et al. Brain volumes and cortical thickness on MRI in the Finnish Geriatric Intervention Study to Prevent Cognitive Impairment and Disability (FINGER). Alzheimers Res Ther. 2019;11(1):53.

51. Smith EE, Cieslak A, Barber P, et al. Therapeutic strategies and drug development for vascular cognitive impairment. J Am Heart Assoc. 2017;6(5):pii: e005568. 